\title{
Esophagectomy via upper partial sternotomy for esophageal cancer after previous right pneumonectomy: A case report
} \author{
Shinji Mine, MD, PhD, Tokyo, Japan \\ From the Department of Gastroenterological Surgery, Gastroenterology Center, The Cancer Institute Hospital of \\ Japanese Foundation for Cancer Research, Tokyo, Japan. \\ There was no funding for this work. \\ Disclosures: Authors have nothing to disclose with regard to commercial support. \\ Received for publication June 18, 2018; revisions received July 23, 2018; accepted for publication Aug 11, 2018. \\ Address for reprints: Masayuki Watanabe, MD, PhD, Department of Gastroenterological Surgery, The Cancer \\ Institute Hospital of Japanese Foundation for Cancer Research, 3-8-31 Ariake, Koto-ku, Tokyo 135-8550, \\ Japan (E-mail: masayuki.watanabe@jfcr.or.jp). \\ J Thorac Cardiovasc Surg 2018; 156:e217-20 \\ $0022-5223 / \$ 36.00$ \\ Copyright (C) 2018 Published by Elsevier Inc. on behalf of The American Association for Thoracic Surgery \\ https://doi.org/10.1016/j.jtcvs.2018.08.093
}

Akihiko Okamura, MD, PhD, Masayuki Watanabe, MD, PhD, Masaru Hayami, MD, PhD, and
- Video clip is available online.

Esophagectomy after a right pneumonectomy is challenging. The anatomic and adhesive changes make it difficult for the surgeon to perform oncologic esophagectomy. ${ }^{1,2}$

Here we present the case of a patient with esophageal cancer with upper mediastinal lymph node metastasis, which was identified 13 years after a right pneumonectomy. We successfully performed esophagectomy with upper mediastinal lymphadenectomy through an upper partial sternotomy combined with laparoscopically assisted transhiatal dissection in this patient.

\section{CLINICAL SUMMARY}

A 66-year-old man with a history of right pneumonectomy for non-small cell lung cancer performed 13 years previously presented with dysphagia. His endoscopy revealed a protruding tumor at the upper third of the esophagus (Figure 1, A). Biopsy of this tumor revealed squamous cell carcinoma. A chest radiograph demonstrated complete opacification of the right hemithorax, a severe mediastinal shift to the right, and overexpansion of the left lung (Figure 1,B). Computed tomography revealed esophageal wall thickening at the cervicothoracic junction and a swollen lymph node along the right recurrent laryngeal nerve (RLN; Figure 1, C). Fludeoxyglucose F 18 (INN fludeoxyglucose $\left[{ }^{18} \mathrm{~F}\right]$ ) positron emission tomography also revealed fludeoxyglucose

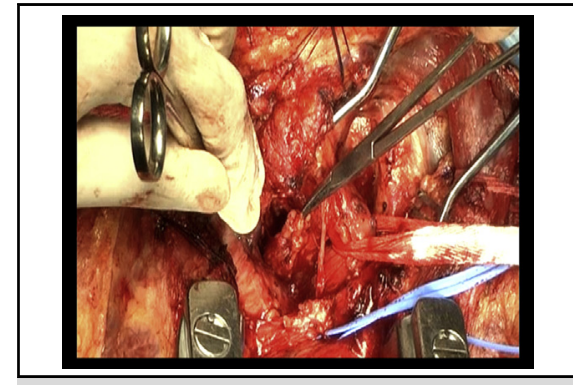

Right upper mediastinal lymphadenectomy through an upper partial sternotomy.

\section{Central Message}

Esophagectomy after a right pneumonectomy is challenging. We performed upper mediastinal lymphadenectomy via partial sternotomy combined with laparoscopic transhiatal esophagectomy in this situation.

See Editorial Commentary page e221.

F 18-avid lesions (Figure 1, D). Accordingly, we diagnosed this tumor as cT2N1M0 esophageal squamous cell carcinoma. Respiratory function was acceptable. Chemoradiotherapy was not recommended because of its potential toxic effect on the left lung. Neoadjuvant chemotherapy was administered before the surgery according to the "Guidelines for Diagnosis and Treatment of Carcinoma of the Esophagus April 2012 Edited by the Japan Esophageal Society." 3 After the completion of neoadjuvant chemotherapy, surgery was planned.

As shown in Figure 2 and Video 1, the patient first underwent cervical and upper mediastinal lymphadenectomy through an upper partial sternotomy. The cervical incision was extended downward in the midline of the sternum. An inverted L-shaped partial sternotomy was performed to the third intercostal space. On the left side, the left paratracheal lymphatic chain was dissected after the identification of a left recurrent laryngeal nerve. On the right side, a right RLN was identified, and the right paratracheal lymphatic chain including the metastatic node was detached from the surrounding tissue, maintaining 

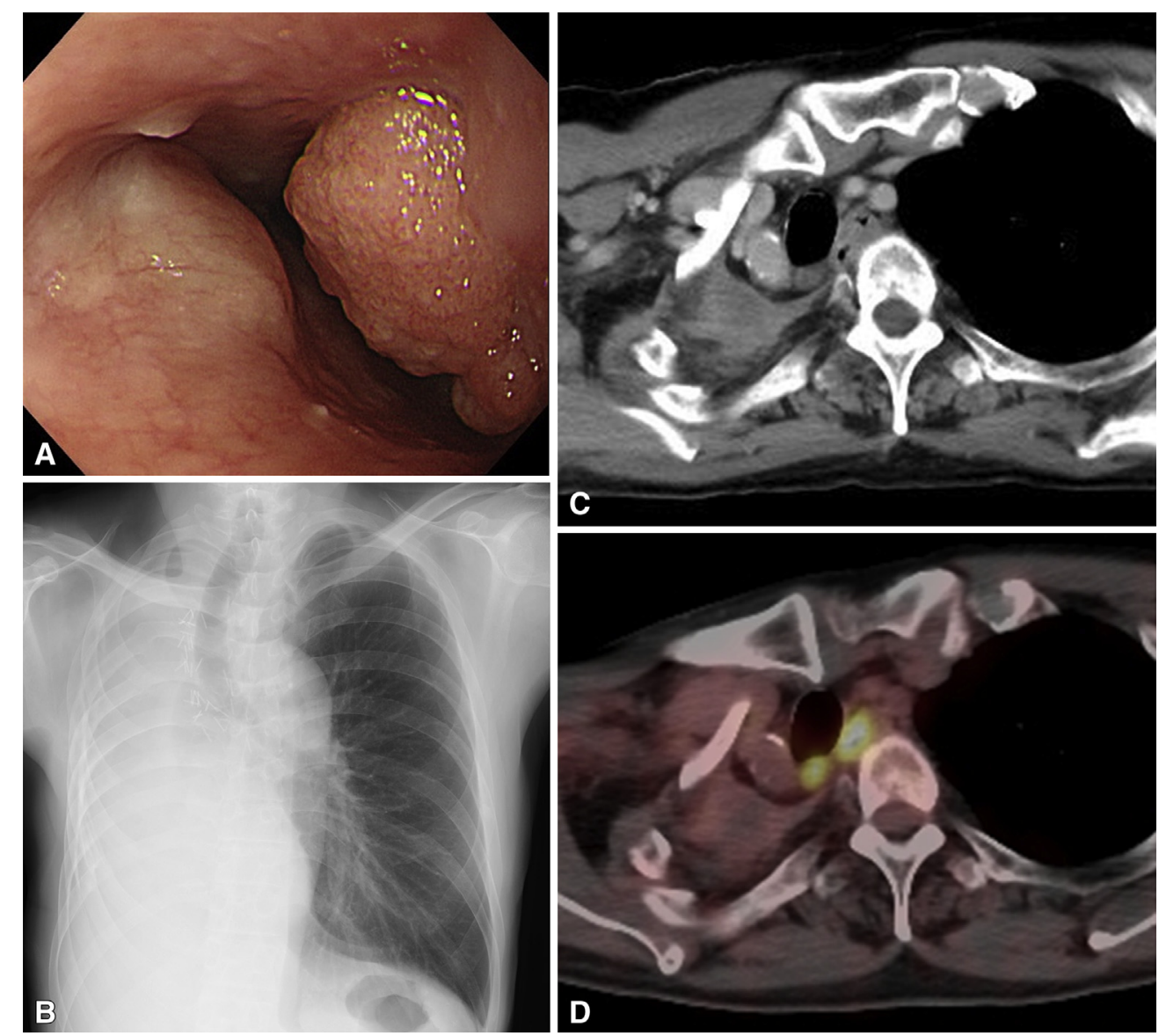

FIGURE 1. Preoperative images. A, Endoscopy showing a protruding tumor at the upper third of the esophagus. B, A chest radiograph demonstrating severe mediastinal shift to the right and overexpansion of the left lung. C and D, Both computed tomography (C) and positron emission tomography with computed tomography (D) revealed esophageal cancer at the cervicothoracic junction and a metastatic lymph node along the right recurrent laryngeal nerve.

the connection between the chain and the esophagus. After that, the cervical esophagus was circumferentially dissected and taped. When the trachea was retracted to the right and the cervical esophagus to the left, we could pull out the chain and successfully dissect the metastatic node.

After that, laparoscopic gastric mobilization and transhiatal mediastinal dissection were performed. When using this approach, we could perform mediastinal dissection further to the level of the left main bronchus; however, we encountered the dense adhesion around the bronchus because of the previous pneumonectomy. After the abdominal esophagus was divided with a linear stapler, a $16 \mathrm{~F}$ tube was inserted from the mouth to the stump of the esophagus. We then fixed the tip of the tube and a long tape to the stump, and the esophagus was everted by pulling the tube toward the mouth. We finally resected the esophagus by eversion stripping. Next, a narrow gastric tube was created through a minilaparotomy, and a cervical esophagogastrostomy was performed by hand sewing through the posterior mediastinal route with this tape. Finally, a pedicled omental flap was placed around the anastomosis.

On postoperative day 8 , saliva emission from the cervical wound was observed, and a persistent anastomotic leak developed that required percutaneous drainage and antibiotic treatment. Severe sternal infection did not develop, however, and the leak improved without any surgical intervention. The patient was discharged on postoperative day 52. No other complications occurred. Pathologic examination revealed ypT1bN1M0, and 1 of the 34 harvested lymph nodes tested positive for metastasis, which was detected preoperatively. After 3-month follow-up, the patient is doing well. 

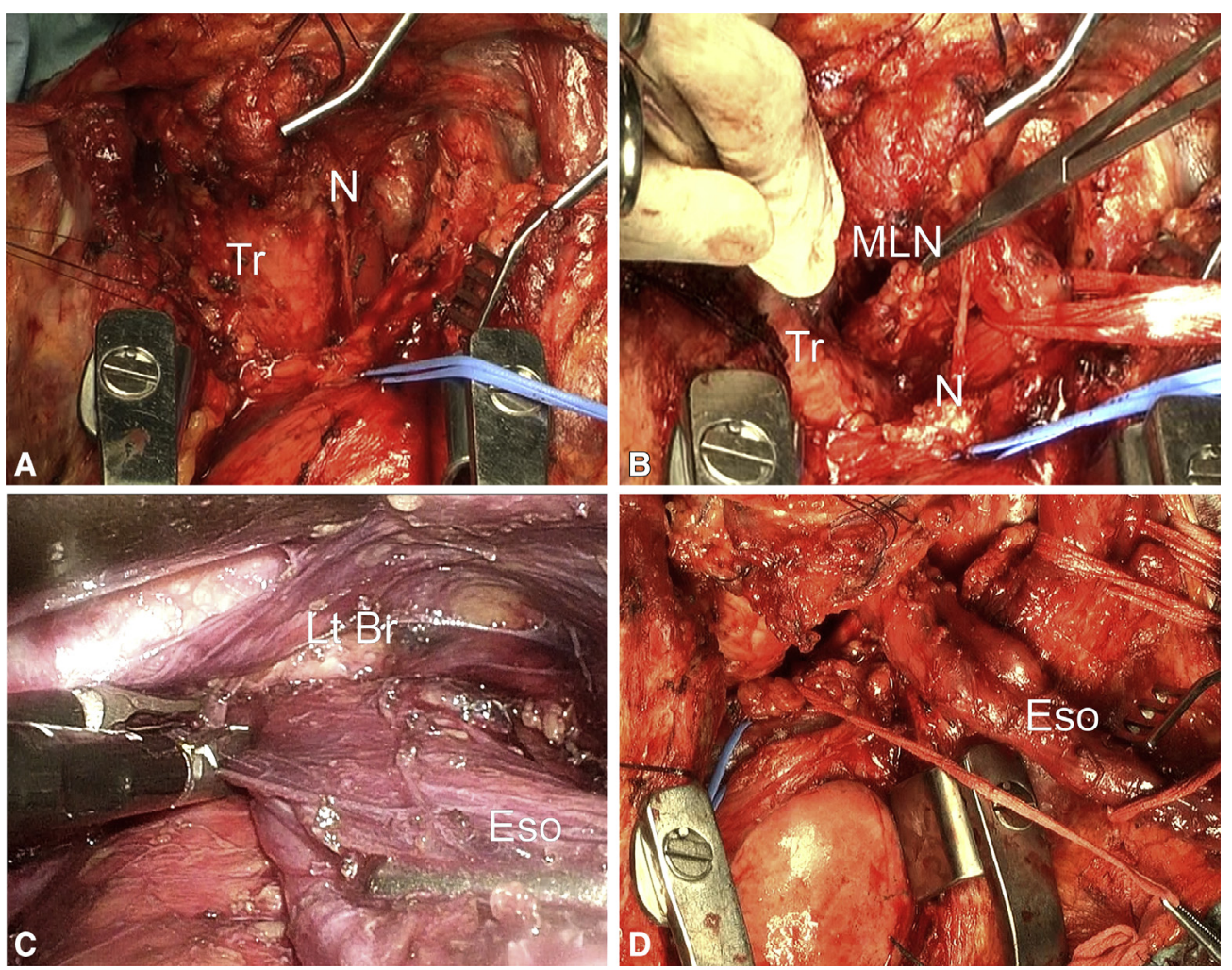

FIGURE 2. Operative images. A. Left lymphatic chain along the recurrent laryngeal nerve $(N)$ was dissected from the cervical operative field by partial sternotomy after the left nerve was identified. B, Right lymphatic chain including metastatic lymph node (MLN) was dissected from the left side. C, Laparoscopic transhiatal mediastinal dissection after completion of the cervical and upper mediastinal lymphadenectomy; mediastinal dissection was performed further to the level of the left main bronchus ( $\mathrm{Lt} \mathrm{Br}$ ). D, Esophagus (Eso) resection by eversion stripping. Tr, Trachea.

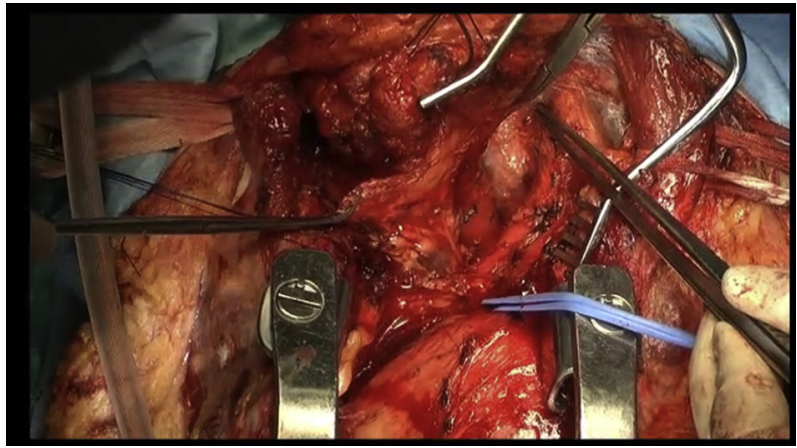

VIDEO 1. The patient first underwent cervical and upper mediastinal lymphadenectomy through an upper partial sternotomy. Left paratracheal lymphatic chain was dissected after the identification of a left recurrent laryngeal nerve. On the right side, a right recurrent laryngeal nerve was identified, and right paratracheal lymphatic chain including the metastatic node was successfully dissected. After completion of the cervical and upper mediastinal lymphadenectomy, laparoscopic gastric mobilization and transhiatal mediastinal dissection were performed. We encountered the dense adhesion around the bronchus because of previous pneumonectomy. We finally resected the esophagus by eversion stripping. After that, a narrow gastric tube was created, and a cervical esophagogastrostomy was performed by hand sewing through the posterior mediastinal route. Video available at: https://www.jtcvs.org/article/S0022-5223(18)32488-7/fulltext.

\section{DISCUSSION}

Esophagectomy after a previous right pneumonectomy is rare. There are 2 reported cases of esophagectomy after a previous right pneumonectomy (Table 1). ${ }^{1,2}$ Both transhiatal and transthoracic approaches were difficult because of dense adhesion and extensive, thick fibrosis. In this situation, how we should approach is unclear, and it is one of the greatest challenges. Although eversion stripping with transhiatal dissection is a useful technique, it is oncologically insufficient without complete upper mediastinal lymphadenectomy; however, lymphadenectomy along RLNs in patients with severe tracheal deviation is technically challenging. Partial sternotomy for esophagectomy was previously reported as a useful technique for the dissection of the upper third of the esophagus. ${ }^{4,5}$ This method allowed the facile direct anterior approach for the complete dissection of the lymph nodes around RLNs. This is the first report of an upper mediastinal lymphadenectomy through an upper partial sternotomy combined with laparoscopically assisted transhiatal esophagectomy for esophageal cancer after a previous pneumonectomy. 
TABLE 1. Reported cases of esophagectomy after a previous right pneumonectomy

\begin{tabular}{|c|c|c|c|c|c|c|c|}
\hline Reference & Age (y) & Sex & Histology & Tumor location & Approach & $\begin{array}{l}\text { Postoperative } \\
\text { complication }\end{array}$ & $\begin{array}{l}\text { Length of } \\
\text { stay (d) }\end{array}$ \\
\hline Reardon et al, ${ }^{1} 2000$ & 54 & M & Adenocarcinoma & Distal esophagus & Transthoracic approach & Pneumonia & 12 \\
\hline Velotta et $\mathrm{al}^{2}, 2014$ & 64 & $\mathrm{~F}$ & Adenocarcinoma & Distal esophagus & Transhiatal approach & Hypercarbia & 34 \\
\hline Our case, 2018 & 66 & M & Squamous cell carcinoma & Proximal esophagus & $\begin{array}{l}\text { Partial sternotomy and } \\
\text { transhiatal approach }\end{array}$ & Anastomotic leak & 52 \\
\hline
\end{tabular}

\section{References}

1. Reardon MJ, Estrera AL, Conklin LD, Reardon PR, Brunicardi FC, Beall AC. Esophagectomy after pneumonectomy: a surgical challenge. Ann Thorac Surg. 2000;69:286-8.

2. Velotta JB, Vasquez CR, Sugarbaker DJ. Transhiatal esophagectomy after previous right pneumonectomy. J Thorac Cardiovasc Surg. 2014;148: e150-2.
3. Kuwano H, Nishimura Y, Oyama T, Kato H, Kitagawa Y, Kusano M, et al. Guidelines for diagnosis and treatment of carcinoma of the esophagus April 2012 edited by the Japan Esophageal Society. Esophagus. 2015;12:1-30.

4. Orringer MB. Partial median sternotomy: anterior approach to the upper thoracic esophagus. J Thorac Cardiovasc Surg. 1984;87:124-9.

5. Kirk RM. Partial and complete sternotomy for blunt oesophagectomy. Br J Surg. 1987;74:685-7. 